\title{
Analysis and Modeling of Magnetic Characteristics in Surface- Mounted Permanent-Magnet Machines with Rotor Overhang
}

\author{
Han-Kyeol Yeo *, Dong-Kyun Woo *, Dong-Kuk Lim *, \\ Jong-Suk Ro *, and Hyun-Kyo Jung *
}

\begin{abstract}
The rotor overhang is used to enhance air-gap flux and improve power density. Due to asymmetry in the axial direction caused by the overhang, the time consuming 3D analysis is necessary to design the motor with overhang. To solve this problem, this paper proposes the equivalent magnetic circuit model (EMCM) that can consider overhang effects without the 3D analysis by using effective air-gap length. The analysis time can be reduced significantly via the proposed EMCM. The reduction of the analysis time is essential for the preliminary design of the motor. In order to verify the proposed model, the 3-D finiteelement method (FEM) analysis is adopted. 3-D FEM results confirm the validity of the proposed EMCM.
\end{abstract}

Keywords: Analytical method, Equivalent magnetic circuit model, Rotor overhang, Surfacemounted permanent-magnet machine

\section{Introduction}

Permanent-magnet (PM) brushless machines are increasingly being used in various applications such as electric vehicles, industrial servos and wind power generation [1]. This is due to their high torque, high power density, high efficiency, and low maintenance as a consequence of the use of PM materials in the rotor. Surface-mounted permanent-magnet (SPM) motors have the advantages of low torque ripple and low cogging torque as compared with interior permanent-magnet (IPM) machines. Generally, these characteristics are important in traction system.

The overhang is defined as the configuration that the rotor length is longer than the stator length in the axial direction in this paper. In general, the overhang structure is used to enhance air-gap flux and improve power density while utilizing free space caused by the stator end winding [2]. 3-D finite-element method (FEM) is necessary in order to analyze the magnetic fields in the axial direction and consider overhang effects. Although 3-D FEM can precisely obtain magnetic flux distribution in SPM motors with overhang, it is time consuming and computationally expensive. Therefore, analytical methods are essential in

Dept. of Electrical and Computer Engineering, Seoul National University, Korea. (gksruf88@elecmech.snu.ac.kr, underdamp @ snu.ac.kr, 1dk8745@gmail.com, jongsukro@naver.com, hkjung @snu.ac.kr)

Received 13 September 2013; Accepted 28 October 2013 the preliminary design of electric machines.

The equivalent magnetic circuit model (EMCM) is widely used as an analytical method for various types of machines, e.g., SPM machines [3]-[5], IPM machines [6], [7], flux-switching PM machines [8], etc. In case of SPM motors, the EMCM for analytically predicting the air-gap and magnet flux density has been developed taking into account leakage flux around the magnets in the rotor [3]. However, overhang effects in SPM machines with rotor overhang have not been included in the EMCM. In this paper, we propose the EMCM considering not only leakage flux in the rotor but also the overhang effects for SPM machines with rotor overhang. 3-D FEM analysis is used to verify the proposed model.

\section{Analytical Model of SPM Machines with Overhang}

Although the effects of slots of stator can be taken into account [3]-[5], [7], [8], the EMCM ignoring the slotting effects was developed in order to focus on the overhang effects and simplify the analytical model in this paper. It is assumed that the effects of saturation within the core are negligible, since the magnetic flux density within the core is low in general and normally there is no significant saturation.

By using the motor topology which is generalized as the linear translation type as shown in Fig. 1, it is possible to 
derive the EMCM applicable to any specific topology. In order to enhance air-gap flux and improve power density, the overhang structure is used in the linear translation motor as shown in Fig. 2.

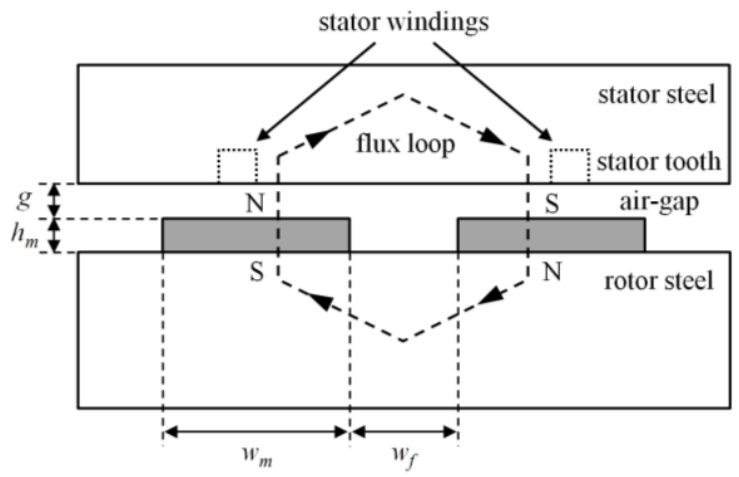

Fig. 1. The linear translational motor topology

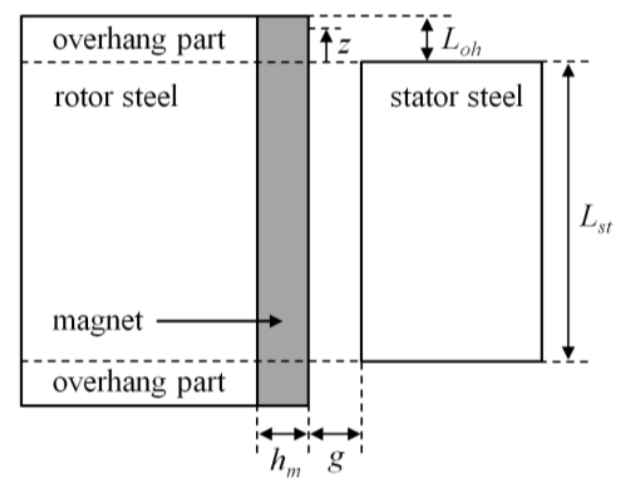

Fig. 2. The configuration of the motor with overhang

Qu et al. developed the EMCM for SPM machines that takes into account the air-gap leakage fluxes around magnets [3]. The air-gap leakage fluxes are the magnet-tomagnet leakage flux and the magnet-to-rotor leakage flux. By using the circular-arc straight-line permeance model [9], these leakage fluxes have been modeled. However, this analytical model cannot be applied to the SPM motors with the overhang because the overhang results in the asymmetry of magnetic fields in the axial direction.

The EMCM based on the analytical model developed by $\mathrm{Qu} e t a l$. is proposed considering overhang effects as well as air-gap leakage fluxes. Fig. 3 shows the proposed EMCM. The variables shown in Fig. 3 are defined as follows:

$\Phi_{g}$ : the air-gap flux excited by one magnet pole

$\Phi_{r}$ : the flux source of one magnet pole

$R_{g}$ : the reluctance corresponding to $\Phi_{g}$

$R_{m o}$ : the reluctance corresponding to $\Phi_{r}$

$R_{r}:$ the reluctance of rotor yoke

$R_{m m}$ : the reluctance corresponding to magnet-to-magnet leakage flux

$R_{m r}$ : the reluctance corresponding to magnet-to-rotor leakage flux.

$R_{r}$ and $R_{s}$ can be ignored due to the assumption mentioned before. Fig. 3 can be simplified into Fig. 4 by using symmetry. In Fig. $4, R_{m}$ is calculated from Fig. 3 as

$$
R_{m}=\frac{R_{m o}}{1+2 \eta+4 \lambda},
$$

where

$$
\begin{aligned}
& \eta=\frac{R_{m o}}{R_{m r}} \\
& \lambda=\frac{R_{m o}}{R_{m m}} .
\end{aligned}
$$

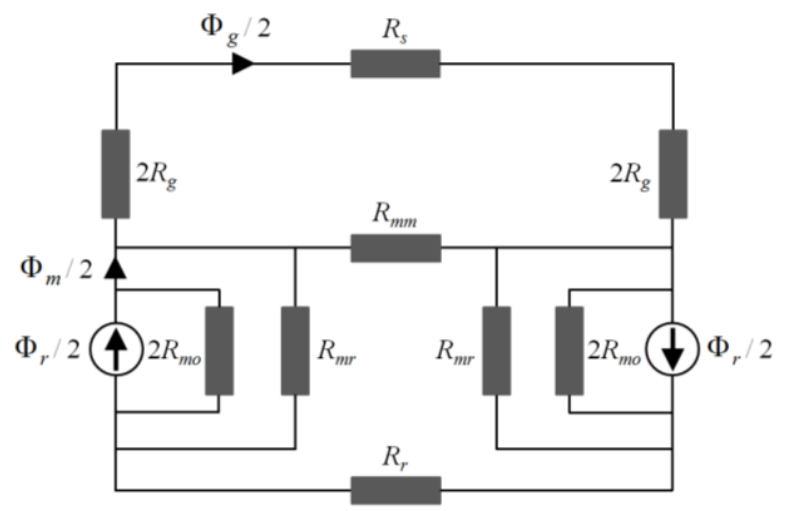

Fig. 3. Equivalent magnetic circuit for Fig. 1 and Fig. 2

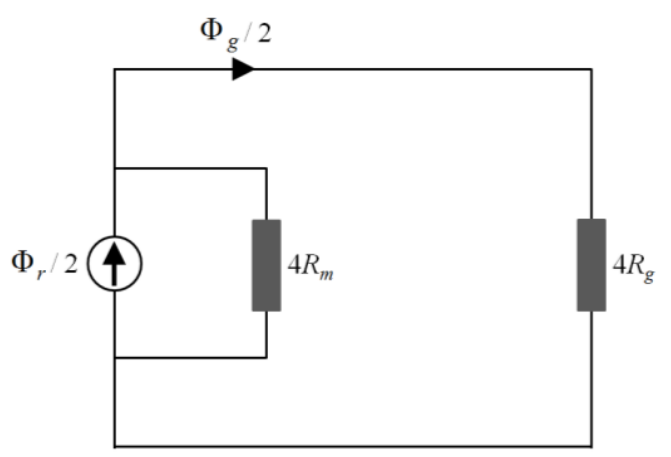

Fig. 4. Simplified circuit of Fig. 3

For the EMCM considering overhang effect, the effective air-gap length is derived via the modeling of the flux line with the circular arc and the straight line as

$$
g_{e}=\left\{\begin{array}{ll}
\sqrt{g^{2}+z^{2}} & 0<z \leq g \\
\frac{\pi}{2} z & g<z
\end{array},\right.
$$


where $z$ is the position in the overhang as shown in Fig. 2 and $g$ is the air-gap length.

The permeances in the non-overhang region is derived in [3] as

$$
\begin{gathered}
P_{g}^{\prime}=\frac{\mu_{0}\left(w_{m}+2 g\right) L_{s t}}{g} \\
P_{m o}^{\prime}=\frac{\mu_{0} \mu_{r} w_{m} L_{s t}}{h_{m}} \\
P_{m m}^{\prime}=\frac{\mu_{0} L_{s t}}{\pi} \ln \left(1+\frac{\pi g}{w_{f}}\right) \\
P_{m r}^{\prime}=\frac{\mu_{0} L_{s t}}{\pi} \ln \left[1+\frac{\pi \min \left(g, w_{f} / 2\right)}{h_{m}}\right]
\end{gathered}
$$

where $\mu_{0}$ is the permeability of air, $\mu_{r}$ is the magnet relative recoil permeability, $L_{s t}$ is the stator stack length, $g$ is the air-gap length, $w_{f}$ is the width between two adjacent magnets, $w_{m}$ is magnet width, $h_{m}$ is magnet length, and $\min (\cdot)$ is the minimum function.

By using the effective air-gap length $g_{e}$, the permeances of infinitesimal stack length $d z$ in the overhang can be derived. The permeances can be calculated by integrating the permeances of infinitesimal stack length over the overhang length as

$$
\begin{aligned}
& P_{g}^{\prime \prime}= \begin{cases}\int_{0}^{L_{o h}} \frac{\mu_{0}\left(w_{m}+2 \sqrt{g^{2}+z^{2}}\right)}{\sqrt{g^{2}+z^{2}}} d z, \quad\left(g \geq L_{o h}\right) \\
\int_{0}^{g} \frac{\mu_{0}\left(w_{m}+2 \sqrt{g^{2}+z^{2}}\right)}{\sqrt{g^{2}+z^{2}}} d z \\
+\int_{g}^{L_{o h}} \frac{2 \mu_{0}\left(w_{m}+\pi z\right)}{\pi z} d z, \quad\left(g<L_{o h}\right)\end{cases} \\
& P_{m o}^{\prime \prime}=\frac{\mu_{0} \mu_{r} w_{m} L_{o h}}{h_{m}} \\
& \iint_{0}^{L_{o h}} \frac{\mu_{0}}{\pi} \ln \left(1+\frac{\pi \sqrt{g^{2}+z^{2}}}{w_{f}}\right) d z, \quad\left(g \geq L_{o h}\right) \\
& P_{m m}^{\prime \prime}=\left\{\int_{0}^{g} \frac{\mu_{0}}{\pi} \ln \left(1+\frac{\pi \sqrt{g^{2}+z^{2}}}{w_{f}}\right) d z\right. \\
& +\int_{g}^{L_{o h}} \frac{\mu_{0}}{\pi} \ln \left(1+\frac{\pi^{2} z}{2 w_{f}}\right) d z, \quad\left(g<L_{o h}\right)
\end{aligned}
$$

$$
P_{m r}^{\prime \prime}=\left\{\begin{array}{l}
\int_{0}^{L_{o h}} \frac{\mu_{0}}{\pi} \ln \left[1+\frac{\pi \min \left(\sqrt{g^{2}+z^{2}}, \frac{w_{f}}{2}\right)}{h_{m}}\right] d z,\left(g \geq L_{o h}\right) \\
\int_{0}^{g} \frac{\mu_{0}}{\pi} \ln \left[\begin{array}{c}
\pi \min \left(\sqrt{g^{2}+z^{2}}, \frac{w_{f}}{2}\right) \\
h_{m}
\end{array}\right] d z \\
+\int_{g}^{L_{o b}} \frac{\mu_{0}}{\pi} \ln \left[1+\frac{\pi \min \left(\pi z / 2, \frac{w_{f}}{2}\right)}{h_{m}}\right] d z,\left(g<L_{o h}\right)
\end{array}\right.
$$

where $L_{o h}$ is the rotor overhang length.

By using the permeances in the non-overhang region and overhang region, the permeances for the whole motor with overhang are derived as

$$
\begin{gathered}
P_{g}=P_{g}^{\prime}+2 P_{g}^{\prime \prime} \\
P_{m o}=P_{m o}^{\prime}+2 P_{m o}^{\prime \prime} \\
P_{m m}=P_{m m}^{\prime}+2 P_{m m}^{\prime \prime} \\
P_{m r}=P_{m r}^{\prime}+2 P_{m r}^{\prime \prime} .
\end{gathered}
$$

Using the above equations and the reciprocal relationship between permeance and reluctance, the reluctances are calculated as

$$
\begin{aligned}
& R_{g}=\frac{1}{P_{g}} \\
& R_{m o}=\frac{1}{P_{m o}} \\
& R_{m m}=\frac{1}{P_{m m}} \\
& R_{m r}=\frac{1}{P_{m r}} .
\end{aligned}
$$

By flux division, the air-gap flux and the flux from the magnet can be derived as

$$
\Phi_{g}=\frac{\Phi_{r}}{1+\left(\frac{R_{g}}{R_{m o}}\right)(1+2 \eta+4 \lambda)}
$$


and

$$
\Phi_{m}=\frac{1+\left(\frac{R_{g}}{R_{m o}}\right)(2 \eta+4 \lambda)}{1+\left(\frac{R_{g}}{R_{m o}}\right)(1+2 \eta+4 \lambda)} .
$$

The air-gap flux density and the magnet flux density can be induced by:

$$
\begin{gathered}
B_{g}=\frac{\frac{A_{m}}{A_{g}}}{1+\left(\frac{R_{g}}{R_{m o}}\right)(1+2 \eta+4 \lambda)} B_{r}, \\
B_{m}=\frac{1+\left(\frac{R_{g}}{R_{m o}}\right)(2 \eta+4 \lambda)}{1+\left(\frac{R_{g}}{R_{m o}}\right)(1+2 \eta+4 \lambda)} B_{r},
\end{gathered}
$$

where

$$
\begin{gathered}
A_{m}=w_{m}\left(L_{s t}+2 L_{o h}\right) \\
A_{g}=\left(w_{m}+w_{f}\right)\left(L_{s t}+2 L_{o h}\right) .
\end{gathered}
$$

\section{Results and Verification}

For the verification of the proposed analytical model, the results from FEM and the analytical results calculated from (23) and (24) are investigated. The investigations are conducted in the various cases with the different $g$ 's, $w_{f}$ 's and $L_{o h}$ 's. We refer to [3] for determining these variables. Table 1 and Table 2 show the results of the motor employing the ferrite magnet with $\mathrm{Br}=0.4 \mathrm{~T}$ and the rare earth magnet with $\mathrm{Br}=1.07 \mathrm{~T}$, respectively.

As can be seen in Table 1 and Table 2, there is little difference between results of the motor employing the ferrite magnet and the rare earth magnet. The accuracy of the EMCM is affected by $L_{o h}$. As the length of the overhang is elongated, the leakage flux at the end of the overhang is increased and the estimation of the magnetic flux path is difficult. This increases the difference between the analytical results and the FEM data. In cases where $L_{o h}$ is below $7 \mathrm{~mm}$, the differences of $B_{m}$ and $B_{g}$ are less than $3 \%$ and $2 \%$, respectively. The differences of $B_{m}$ and $B_{g}$ are less than $5 \%$ and $3 \%$ when $L_{o h}$ is $10 \mathrm{~mm}$, respectively.
Table 1. The comparison between the analytical results and the FEM results of the motor employing ferrite magnets

\begin{tabular}{|c|c|c|c|c|c|c|c|c|}
\hline \multicolumn{2}{|c|}{$\begin{array}{c}\text { Geometrical } \\
\text { dimensions }\end{array}$} & \multicolumn{2}{c|}{$\begin{array}{c}\text { Analytical } \\
\text { results }\end{array}$} & \multicolumn{2}{c|}{$\begin{array}{c}\text { 3D FEM } \\
\text { results }\end{array}$} & \multicolumn{2}{c|}{ Difference* } \\
\hline $\begin{array}{c}g \\
(\mathrm{~mm})\end{array}$ & $\begin{array}{c}w_{f} \\
(\mathrm{~mm})\end{array}$ & $\begin{array}{c}L_{\text {oh }} \\
(\mathrm{mm})\end{array}$ & $B_{m}(\mathrm{~T})$ & $B_{g}(\mathrm{~T})$ & $B_{m}(\mathrm{~T})$ & $B_{g}(\mathrm{~T})$ & $B_{m}(\%)$ & $B_{g}(\%)$ \\
\hline 0.5 & 5.0 & 0.0 & 0.356 & 0.281 & 0.353 & 0.279 & -0.87 & -0.76 \\
\hline 0.5 & 5.0 & 5.0 & 0.353 & 0.278 & 0.347 & 0.275 & -1.78 & -1.24 \\
\hline 0.5 & 5.0 & 7.0 & 0.352 & 0.277 & 0.343 & 0.272 & -2.70 & -1.71 \\
\hline 0.5 & 5.0 & 10.0 & 0.350 & 0.274 & 0.336 & 0.267 & -4.33 & -2.58 \\
\hline 0.5 & 4.0 & 0.0 & 0.356 & 0.292 & 0.354 & 0.290 & -0.61 & -0.89 \\
\hline 0.5 & 4.0 & 5.0 & 0.354 & 0.290 & 0.348 & 0.285 & -1.50 & -1.35 \\
\hline 0.5 & 4.0 & 7.0 & 0.352 & 0.288 & 0.344 & 0.282 & -2.40 & -1.82 \\
\hline 0.5 & 4.0 & 10.0 & 0.351 & 0.285 & 0.337 & 0.278 & -3.99 & -2.67 \\
\hline 1.0 & 5.0 & 0.0 & 0.326 & 0.249 & 0.321 & 0.249 & -1.44 & -0.24 \\
\hline 1.0 & 5.0 & 5.0 & 0.323 & 0.246 & 0.317 & 0.246 & -1.94 & -0.14 \\
\hline 1.0 & 5.0 & 7.0 & 0.321 & 0.244 & 0.313 & 0.243 & -2.56 & -0.18 \\
\hline 1.0 & 5.0 & 10.0 & 0.319 & 0.241 & 0.307 & 0.240 & -3.73 & -0.34 \\
\hline 1.0 & 4.0 & 0.0 & 0.326 & 0.259 & 0.322 & 0.258 & -1.35 & -0.35 \\
\hline 1.0 & 4.0 & 5.0 & 0.323 & 0.255 & 0.317 & 0.254 & -1.82 & -0.24 \\
\hline 1.0 & 4.0 & 7.0 & 0.322 & 0.253 & 0.314 & 0.252 & -2.43 & -0.27 \\
\hline 1.0 & 4.0 & 10.0 & 0.320 & 0.250 & 0.308 & 0.248 & -3.56 & -0.40 \\
\hline
\end{tabular}

At $L_{s t}=100.0 \mathrm{~mm}, h_{m}=4.0 \mathrm{~mm}, w_{m}=20.0 \mathrm{~mm}, \mu_{r}=1.05, B_{r}=0.40$.

$*$ : Difference $=(3 \mathrm{D}$ FEM results - Analytical results $) / 3 \mathrm{D}$ FEM results $\times 100$.

Table 2. The comparison between the analytical results and the FEM results of the motor employing rare earth magnets

\begin{tabular}{|c|c|c|c|c|c|c|c|c|}
\hline \multicolumn{2}{|c|}{$\begin{array}{c}\text { Geometrical } \\
\text { dimensions }\end{array}$} & \multicolumn{2}{c|}{$\begin{array}{c}\text { Analytical } \\
\text { results }\end{array}$} & \multicolumn{2}{c|}{$\begin{array}{c}\text { 3D FEM } \\
\text { results }\end{array}$} & \multicolumn{2}{c|}{ Difference $^{*}$} \\
\hline $\begin{array}{c}g \\
(\mathrm{~mm})\end{array}$ & $\begin{array}{c}w_{f} \\
(\mathrm{~mm})\end{array}$ & $\begin{array}{c}L_{o h} \\
(\mathrm{~mm})\end{array}$ & $B_{m}(\mathrm{~T})$ & $B_{g}(\mathrm{~T})$ & $B_{m}(\mathrm{~T})$ & $B_{g}(\mathrm{~T})$ & $B_{m}(\%)$ & $B_{g}(\%)$ \\
\hline 0.5 & 5.0 & 0.0 & 0.954 & 0.753 & 0.946 & 0.747 & -0.85 & -0.74 \\
\hline 0.5 & 5.0 & 5.0 & 0.947 & 0.745 & 0.930 & 0.736 & -1.77 & -1.23 \\
\hline 0.5 & 5.0 & 7.0 & 0.943 & 0.741 & 0.919 & 0.729 & -2.69 & -1.71 \\
\hline 0.5 & 5.0 & 10.0 & 0.939 & 0.734 & 0.900 & 0.716 & -4.32 & -2.57 \\
\hline 0.5 & 4.0 & 0.0 & 0.954 & 0.783 & 0.950 & 0.777 & -0.47 & -0.73 \\
\hline 0.5 & 4.0 & 5.0 & 0.947 & 0.775 & 0.934 & 0.765 & -1.36 & -1.22 \\
\hline 0.5 & 4.0 & 7.0 & 0.944 & 0.770 & 0.923 & 0.758 & -2.26 & -1.68 \\
\hline 0.5 & 4.0 & 10.0 & 0.939 & 0.763 & 0.904 & 0.744 & -3.85 & -2.54 \\
\hline 1.0 & 5.0 & 0.0 & 0.873 & 0.668 & 0.861 & 0.667 & -1.44 & -0.21 \\
\hline 1.0 & 5.0 & 5.0 & 0.865 & 0.659 & 0.849 & 0.658 & -1.92 & -0.11 \\
\hline 1.0 & 5.0 & 7.0 & 0.861 & 0.653 & 0.840 & 0.652 & -2.54 & -0.15 \\
\hline 1.0 & 5.0 & 10.0 & 0.855 & 0.645 & 0.824 & 0.643 & -3.70 & -0.32 \\
\hline 1.0 & 4.0 & 0.0 & 0.874 & 0.693 & 0.862 & 0.691 & -1.32 & -0.33 \\
\hline 1.0 & 4.0 & 5.0 & 0.866 & 0.683 & 0.851 & 0.682 & -1.80 & -0.22 \\
\hline 1.0 & 4.0 & 7.0 & 0.862 & 0.677 & 0.842 & 0.676 & -2.41 & -0.24 \\
\hline 1.0 & 4.0 & 10.0 & 0.856 & 0.668 & 0.827 & 0.666 & -3.54 & -0.64 \\
\hline
\end{tabular}

At $L_{s t}=100.0 \mathrm{~mm}, h_{m}=4.0 \mathrm{~mm}, w_{m}=20.0 \mathrm{~mm}, \mu_{r}=1.0384, B_{r}=1.07$.

$*$ : Difference $=(3 \mathrm{D}$ FEM results - Analytical results $) / 3$ D FEM results $\times 100$. 
In the condition of the same stator stack length, the total flux passing through air-gap increases when $L_{o h}$ increases. However, the average flux densities $B_{m}$ and $B_{g}$ decline as the overhang is elongated as shown in Table 1 and Table 2, this is because the area is more increased compared to the flux. In cases where $L_{s t}$ is $100 \mathrm{~mm}$, the total flux passing through air-gap increases by about $11 \%$ and $15 \%$ when $L_{o h}$ is $7 \mathrm{~mm}$ and $10 \mathrm{~mm}$, respectively.

\section{Conclusion}

Since the conventional EMCM cannot consider overhang effects, the time consuming 3D analysis is used for motor design. In this paper, it is meaningful that the time for the electromagnetic field analysis of the machine can be reduced significantly via the proposed EMCM.

\section{References}

[1] J. R. Hendershot, Jr. and T. J. E. Miller, "Design of brushless permanent-magnet motors". Oxford, U.K.: Magna Physics Publishing and Clarendon Press, 1994.

[2] J. P. Wang, D. K. Lieu, W. L. Lorimer, and A. Hartman, "Influence of the permanent magnet overhang on the performance of the brushless de motor," J. Appl. Phys., vol. 83, no. 11, pp. 6362-6364, Jun. 1998.

[3] R. Qu, and T. A. Lipo, "Analysis and modeling of air-gap and zigzag leakage fluxes in a surface-mounted permanentmagnet machine," IEEE Trans. Ind. Appl., vol. 40, no. 1, pp. 121-127, 2004.

[4] M. F. Hsieh, and Y. C. Hsu, "A generalized magnetic circuit modeling approach for design of surface permanent-magnet machines," IEEE Trans. Ind. Electron., vol. 59, no. 2, pp. 779-792, Feb. 2012.

[5] Y. Kano, T. Kosaka, and N. Matsui, "Simple nonlinear magnetic analysis for permanent-magnet motors," IEEE Trans. Ind. Appl., vol. 41, no. 5, pp. 1205-1214, 2005.

[6] L. Zhu, S. Z. Jiang, Z. Q. Zhu, and C. C. Chan, "Analytical modeling of open-circuit air-gap field distributions in multisegment and multilayer interior permanent-magnet machines," IEEE Trans. Magn., vol. 45, no. 8, pp. 3121-3130, Aug. 2009.

[7] C. Mi, M. Filippa, W. Liu, and R. Ma, "Analytical method for predicting the air-gap flux of interior-type permanent-magnet machines," IEEE Trans. Magn., vol. 40, no. 1, pp. 50-58, Jan. 2004.

[8] Z. Q. Zhu, Y. Pang, D. Howe, S. Iwasaki, R. Deodhar, and A. Pride, "Analysis of electromagnetic performance of fluxswitching permanent-magnet machines by nonlinear adaptive lumped parameter magnetic circuit model," IEEE Trans. Magn., vol. 41, no. 11, pp. 4277-4287, Nov. 2005.

[9] D. Hanselman, Brushless Permanent Magnet Motor Design, 2nd ed.: The Writers' Collective, 2003, pp. 15-29.

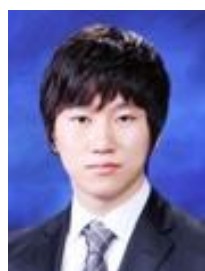

University.
Han-Kyeol Yeo received B.S. degree in electronic and electrical engineering from Sungkyunkwan University, Suwon, Korea, in 2012. He currently researches on the analysis and design of electric machines in electrical engineering, Seoul National

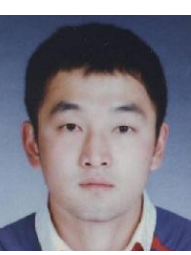

Dong-Kyun Woo received B.S. degree in electrical engineering from Yonsei University, Seoul, Korea, in 2007. He is currently working toward the Ph.D. degree in electrical engineering from the Seoul National University, Seoul, Korea. His current research interests include numerical analysis and design of electrical machines.

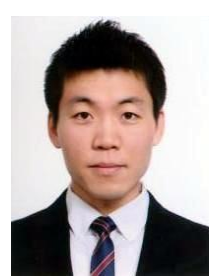

Dong-Kuk Lim received B.S. degree in the electrical engineering from Dongguk University, Seoul, Korea, in 2010. He is currently working toward the Ph.D. degree in electrical engineering and computer science from the Seoul National University, Seoul, Korea. His current research interests include design of electrical machines.

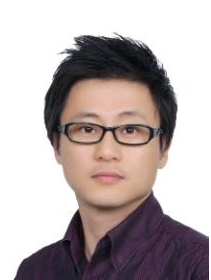

Jong-Suk Ro received B.S. degree in mechanical engineering from Han-Yang University, Seoul, Korea, in 2001. In 2008, he earned a Ph.D. in electrical engineering from Seoul National University, Seoul, Korea, through the Combined Master's and Doctorate Program.

He conducted research on cellular phone modules at R\&D center of Samsung Electronics as a Senior Engineer from 2008 to 2012. From 2012 to 2013, he was at Brain Korea 21 Information Technology of Seoul National University as a Post-Doctoral Fellow. Currently, he is carrying out research at Electrical Energy Conversion System Research Division of Smart Grid Team at Korea Electrical Engineering \& Science Research Institute as a Researcher.

His research interests are numerical analysis and optimal design of electric machines. 


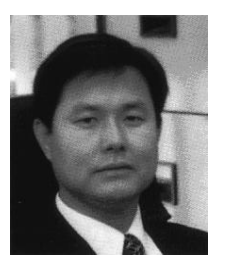

Hyun Kyo Jung received the B.S., M.S., and $\mathrm{Ph} . \mathrm{D}$. degree in Electrical engineering from the Seoul National University, Seoul, Korea, in 1979, 1981, and 1984, respectively. From 1985 to 1994, he was a member of the faculty with Kangwon National University. From 1987 to 1989, he was with the Polytechnic University of Brooklyn, Brooklyn, NY. From 1999 to 2000, he was a Visiting Professor with the University of California at Berkeley. He is currently a Professor at the School of Electrical Engineering and Computer Science/Electrical Engineering, Seoul National University. His research interests are the analysis and design of the electric machine. 